\title{
Superiority of mosapride citrate to picosulfate sodium as a laxative for withdrawal from regular enemas in children with severe functional constipation
}

\author{
Yoshimitsu Fujii' ${ }^{1}$, Eriko Kouhata ${ }^{2}$, Kazunari Kaneko ${ }^{3}$ \\ From ${ }^{1}$ Associate Professor, ${ }^{2}$ Research Associate, ${ }^{3}$ Professor, Department of Pediatrics, Kansai Medical University, Hirakata, Osaka, Japan
}

\begin{abstract}
Background: Severe functional constipation (FC) with low bowel movement frequency (BMF) of $\leq 1$ day/week and hard stools often requires regularly repeated enemas or often leads to enema dependency (ED). Aim: The current study aimed to compare the efficacy of mosapride citrate (Mo) with the traditional stimulant laxative picosulfate sodium (Pi) for withdrawal from ED in children with severe FC. Results: Twenty-four treatment-naïve patients who met the Rome IV diagnostic criteria for FC seen at our center for 8 years from 2012 were enrolled. Glycerin enema was repeated until the BMF was $\geq 3.5$ days $/$ week. Simultaneously, Mo at $0.3 \mathrm{mg} / \mathrm{kg} / \mathrm{day}(\mathrm{n}=11)$ or $\mathrm{Pi}$ at $0.25 \mathrm{mg} / \mathrm{kg} /$ day $(\mathrm{n}=13)$ was administered concomitantly with magnesium oxide or lactulose. The proportion of withdrawal from ED was significantly higher in the Mo group than Pi group during the 4 months observational period $(90.9 \%$ vs. $46.2 \%$, respectively; $\mathrm{p}=0.034)$ and shorter in time to withdraw from $\mathrm{ED}$ ( 0 vs. 3.5 months, respectively; $\mathrm{p}=0.015$ ). Conclusion: Mo is more effective than $\mathrm{Pi}$ for withdrawal from ED in children with severe FC.
\end{abstract}

Key words: Child, Enema, Functional constipation, Mosapride citrate, Picosulfate sodium

$\mathrm{T}$ The prevalence of functional constipation (FC) in children ranges from $0.7 \%$ to $29.6 \%$ [1], making FC one of the most common pediatric digestive diseases. As per the smallscale questionnaire surveys, the prevalence has been reported to be ranged from 5.7 to $31.9 \%$ among the Japanese children [2]. FC often requires pharmacological treatment. However, no clinical studies of FC treatment in Japanese children had high levels of evidence [2]. Mild FC, in which regular hard stools are expelled on their own [3,4], can be treated with monotherapy using osmotic laxatives (OLs) such as polyethylene glycol (PEG) [5]. For severe $\mathrm{FC}$, however, in which the frequency of defecation is highly reduced or absent [6], monotherapy with OLs is often ineffective [7]. In such cases, stimulant laxatives that increase the peristalsis of the gastrointestinal tract are often used in combination with OLs. Transanal treatment is performed when concurrent use of OLs and stimulant laxatives is unsuccessful [2]. Patients with severe FC often depend on regularly repeated enemas to evacuate their rectal stool retention. Because the distress induced by regular enemas compromises patients' quality of life [8], withdrawal from regular enemas with the use of appropriate laxatives is strongly desirable.

Mosapride citrate (Mo) [9-11] was recently added to the list of drugs for the treatment of severe FC in children [2]. Mo is

\section{Access this article online}

Received - 05 July 2021

Initial Review - 24 July 2021

Accepted - 10 Aug 2021

DOI: 10.32677/IJCH.2021.v08.i09.3020 a stimulant laxative that modulates physiological peristalsis of the gastrointestinal tract [11] and has been used in children with reflux esophagitis [12] without adverse events, even with long periods of administration [13]. However, the efficacy of Mo for severe FC in children has not been compared with that of typical traditional stimulant laxatives, such as picosulfate sodium (Pi). Therefore, this study was conducted to determine the efficacy of Mo for withdrawal from enema dependency (ED) in comparison with Pi in pediatric patients with severe FC.

\section{MATERIALS AND METHODS}

This observational study was conducted at our center, starting with patients who visited in 8 years (2012-2020). A flow diagram of study population selection is shown in Fig. 1 [14]. Disimpaction was performed using a $50 \%$ glycerin enema (GE) at a dose of $3 \mathrm{~mL} / \mathrm{kg}$ in all participants if fecal impaction in the anus was confirmed on the first visit. Additional GEs at the same dose were repeated on alternative days until bowel movement frequency (BMF) achieved $>3.5$ days per week. The patients were then allocated to either the Mo group $(n=11)$ or Pi group $(n=13)$. As the stimulant laxative, only Pi was used until December 2013. After January 2014, when Mo was included in the Japanese guideline, the patients were allowed to choose either Mo or Pi. The patients in the Mo group received Mo at a dose of $0.3 \mathrm{mg} / \mathrm{kg} /$ day

Correspondence to: Kazunari Kaneko, Department of Pediatrics, Kansai Medical University, Hirakata, Osaka, Japan. E-mail: kanekok@hirakata.kmu.ac.jp

(C) 2021 Creative Commons Attribution-NonCommercial 4.0 International License (CC BY-NC-ND 4.0). 


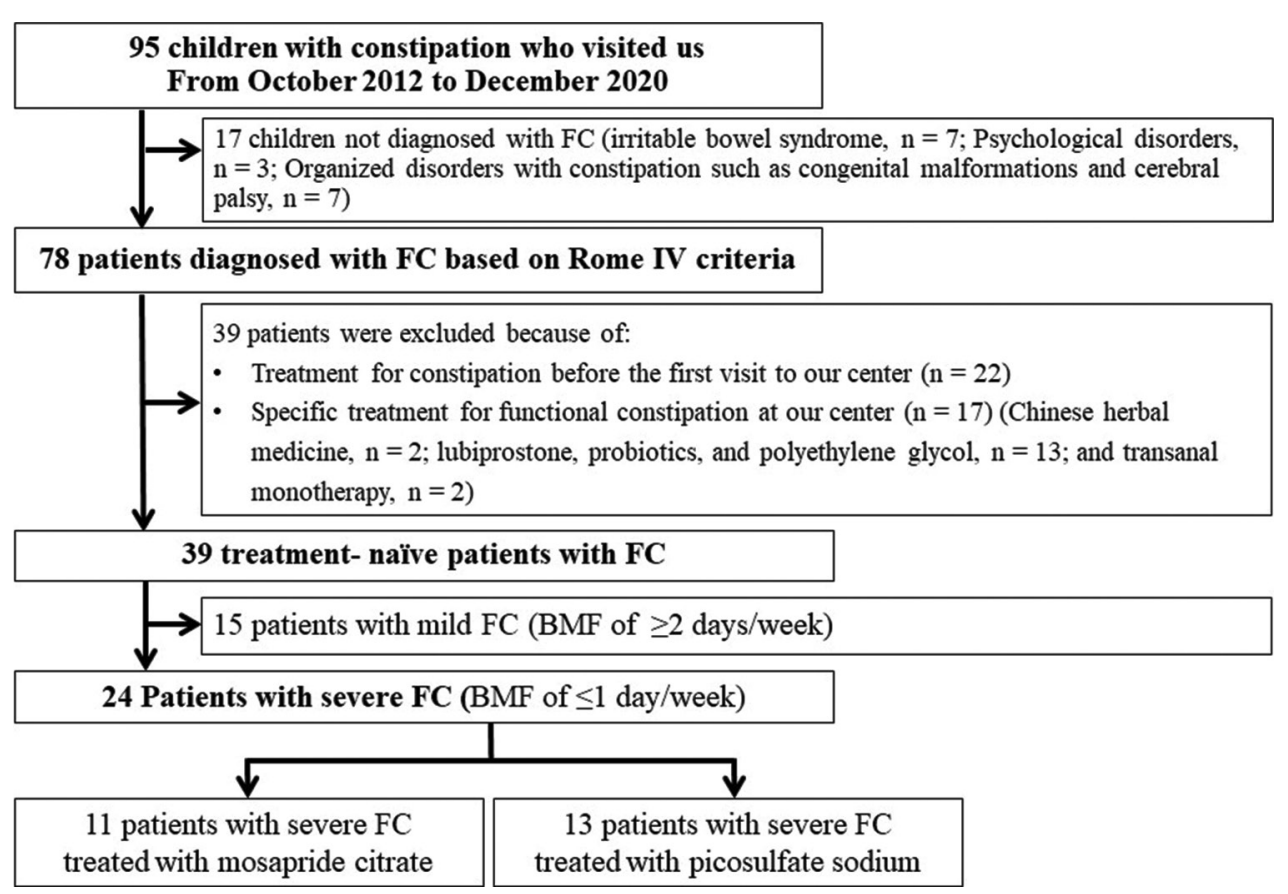

Figure 1: Flow diagram of the population selection procedure

throughout the treatment period $[9,10]$, while the patients in the $\mathrm{Pi}$ group received $\mathrm{Pi}$ at an initial dose of $0.25 \mathrm{mg} / \mathrm{kg} / \mathrm{day}$ from the $3^{\text {rd }}$ day after the first visit. This is because Pi may cause abdominal pain due to forced hyperperistalsis in patients with fecal impaction. The administered dose and interval of Pi were titrated according to the BMF [4]. In addition, all participants in both groups received daily administration of either magnesium oxide $(\mathrm{Mg})(0.06 \mathrm{~g} / \mathrm{kg} /$ day $)$ or lactulose $(1.0 \mathrm{~g} / \mathrm{kg} /$ day $)$ throughout the treatment period. The doses of these additional drugs were also titrated according to age, weight, and symptoms. After a 4-month treatment period, the background information such as sex, age, BMF, Bristol Stool Form Scale (BSFS), ED, withdrawal from $\mathrm{ED}$ (WE), and treatment period were extracted from the patients' medical records and compared between the Mo and the Pi group.

The following definition of terms was used. ED: $>50 \%$ of defecations induced by GEs during the most recent 4-week period. Assessments related to therapeutic efficacy were defined as follows $[2,4,9,10,15]$; BMF: The number of days per week on which defecation was achieved without a GE; treatment success (TS): BMF of $\geq 3$ and BSFS of $\geq 3$ without meeting the Rome diagnostic criteria for pediatric FC during 4 weeks; WE: Maintenance of TS without GEs; the time to WE: The number of days between the initial and final GE; and failure of WE: Failure to achieve TS despite 4 months of GE treatment.

Categorical data and numerical data were compared between the two groups using Fisher's exact test and the Mann-Whitney U-test, respectively. $\mathrm{p}<0.05$ was considered statistically significant. EZR software (version 1.33; https://do.org/10.1038/ bmt.2012.244) and G*Power software (version 3.1.9.7; https://www.psychologie.hhu.de/arbeitsgruppen/allgemeinepsychologie-und-arbeitspsychologie/gpower.html) were used for analyses.

\section{RESULTS}

The Mo group comprised 11 patients, and the Pi group comprised 13 patients. All patients met the definition of ED and controlled their defecation at their own discretion using GEs available over the counter until they received specialized treatment for constipation at our center. The background information of the two groups is shown in Table 1. There were no significant differences in background features between the Mo group and Pi group.

In contrast, the proportion of patients who achieved WE within the 4-month observational period was significantly higher in the Mo group (10/11 patients: 90.9\%) than the Pi group (6/13 patients: $46.2 \%)(p=0.034)$. After excluding the patients who failed to achieve WE, per-protocol analysis was performed among the patients who achieved WE (Mo group: 10 patients; Pi group: 6 patients). Table 2 represents a comparison of patients who achieved WE dependency within 4 months of treatment with either Mo or Pi.

All 24 participants, including the patients who failed to achieve WE and interchanged Mo and Pi, finally achieved TS in 36 months. No adverse events, including abdominal pain, were observed in either group. Blood tests were performed in 4 (30.8\%) patients in the Pi group and 11 (100\%) patients in the Mo group, and no abnormalities were found.

\section{DISCUSSION}

Although FC is common in childhood, treatment strategies including GEs and the choice of laxatives are not yet established in Japan. In particular, patients with severe FC (defined as BMF of $\leq 1$ day/week) often require regular repeated GEs to evacuate their bowels. Because the distress induced by regular enemas compromises patients' quality of life [8], WE with the use of 
Table 1: Background features of the patients with severe functional constipation at the first visit

\begin{tabular}{|c|c|c|c|}
\hline Background features & $\begin{array}{c}\text { Mo group } \\
(\mathrm{n}=11)\end{array}$ & $\begin{array}{c}\text { Pi group } \\
(n=13)\end{array}$ & p-value \\
\hline Male versus female (number) & 3 versus 8 & 6 versus 7 & 0.423 \\
\hline $\begin{array}{l}\text { Age at enrollment, median } \\
\text { years (range) }\end{array}$ & $\begin{array}{c}2.4 \\
(0.9-13.2)\end{array}$ & $\begin{array}{c}2.3 \\
(1.1-15.0)\end{array}$ & 0.352 \\
\hline $\begin{array}{l}\text { Bowel movement frequency } \\
\text { in days/week (range) }\end{array}$ & $0(0-1)$ & $0(0-1)$ & 0.431 \\
\hline Bristol Stool Form Scale & $1(1-1)$ & $1(1-2)$ & 0.095 \\
\hline $\begin{array}{l}\text { Additional OLs: Mg versus } \\
\text { lactulose, (number of patients) }\end{array}$ & 3 versus 8 & 9 versus 4 & 0.101 \\
\hline
\end{tabular}

Table 2: Comparison of patients who achieved withdrawal from enema dependency within 4 months of treatment with either Mo or Pi

\begin{tabular}{lccc}
\hline \multirow{2}{*}{$\begin{array}{l}\text { Assessments related } \\
\text { to therapeutic efficacy }\end{array}$} & \multicolumn{2}{c}{ Patients who achieved WE } & p-value \\
\cline { 2 - 3 } & with Mo (n=10) & with Pi (n=6) & \\
\hline Time to WE (months) & $0(0-4)$ & $3.5(2-4)$ & 0.015 \\
BMF (days/weeks) & $7(3-7)$ & $4(3-7)$ & 0.142 \\
BSFS & $5(3-6)$ & $4.5(3-5)$ & 0.127 \\
\hline
\end{tabular}

Data presented as median (minimum-maximum), n: Total number of patients, WE: Withdrawal from enema dependency, BMF: Bowel movement frequency, BSFS: Bristol Stool Form Scale, Mo: Mosapride citrate, Pi: Picosulfate sodium

appropriate laxatives is desirable. Mo was recently added to the list of drugs for the treatment of children with severe FC in Japan; therefore, this study was conducted to elucidate the efficacy of Mo for WE in comparison with Pi. As a result, the study showed that Mo is superior to Pi to achieve WE in children with severe FC. The reason why Pi was inferior to Mo is the mechanism of action in vivo: Pi requires transformation by the gut microbiota to be in its active form which acts on and stimulates the colonic mucosa, thereby enhancing acetylcholine release from the nerve fibers [16]. In contrast, Mo is gut microbiota independent [17] and enhances peristalsis by acting directly on the enteric plexus for the release of acetylcholine [18,19]. Gomes and de Morais [20] and de Meij et al. [21] showed that the gut microbiota of pediatric patients with FC differs from that of normal children. Therefore, dysbiosis of the gut microbiota in some patients with FC may result in the inability of Pi to transform into its active form, leading to inferior results. Importantly, our results revealed a difference in efficacy between the pharmacological actions of Pi and Mo because this study excluded the influence of probiotics.

However, the number of patients used in this study, was too small to draw a robust conclusion. A post hoc analysis showed that the power $(1-\beta)$ to detect the differences of the proportions of WE and the time to WE were close to significant level of 0.8 ( 0.786 and 0.757 , respectively). In addition, the choice of the additional $\mathrm{OL}$ was not randomized, and either $\mathrm{Mg}$ or lactulose was administered depending on the patients' preferences. However, we do believe that this did not have strong impact on the present results, considering that there is reportedly no significant difference in the efficacy between $\mathrm{Mg}$ and lactulose [4].
Furthermore, the proportion of patients receiving either $\mathrm{Mg}$ or lactulose was not different between the Mo and the Pi groups in this study. Furthermore, the patients were allowed to choose either Mo or Pi for their treatment. Although there were no significant differences in the patients' background features between the two groups, we cannot completely rule out the possibility that some bias may exist because this study is not a randomized controlled trial. Patients treated with PEG were excluded from the study because PEG was not available in Japan during the start of the study. Míngues et al. [22] and Dziechciarz et al. [23] showed that PEG monotherapy is adequate for disimpaction in children with FC, although it is inferior to enemas [23]. In fact, a procedure similar to enema-free disimpaction has been performed in adults undergoing colonoscopy preparation [24]. Therefore, a future study can be planned to test the efficacy of oral administration of Mo with PEG to achieve enema-free disimpaction. In addition, this study helps to establish new strategies for disimpaction in children with severe FC.

\section{CONCLUSION}

Mo with OL is recommended for the achievement of WE in children with severe FC. A new clinical trial is needed to study the usefulness of PEG with Mo as an enema-free treatment strategy for disimpaction in children with severe FC.

\section{ACKNOWLEDGMENT}

We would like to thank Katsuyasu Kouda, Department of Public Health, Kansai Medical University, for providing support in the statistical analyses. We would also like to thank Scott Wysong and Angela Morben, DVM, ELS of Edanz (https://jp.edanz.com/ ac) for English language editing of a draft of this manuscript.

\section{REFERENCES}

1. van den Berg MM, Benmiga MA, di Lorenzo C. Epidemiology of childhood constipation: A systematic review. Am J Gastroenterol 2006;101:240-9.

2. Japanese Society for Pediatric Gastroenterology, Hepatology and Nutrition, about Children's Constipation for their Healthy Growth; 2021. Available from: http://www.jspghan.org/constipation/files/guideline.pdf. [Last accessed on 2021 Jan 31].

3. Russo M, Martinelli M, Sciorio E, Botta C, Miele E, Vallone G, et al. Stool consistency, but not frequency, correlates with total gastrointestinal transit time in children. J Pediatr 2013;162:1188-92.

4. Fujii Y, Yamanouchi S, Kato S, Washio R, Kitao T, Omachi T, et al. Usefulness of the Bristol stool form scale in the diagnosis and the severity assessment of pediatric functional constipation. J Jpn Pediatr Soc 2014;118:791-6. Available from: https://ndlonline.ndl.go.jp/\#!/detail/ R300000002-I025546231-00. [Last accessed on 2021 Aug 21].

5. Gordon M, MacDonald JK, Parker CE, Akobeng AK, Thomas AG. Osmotic and stimulant laxatives for the management of childhood constipation. Cochrane Database Syst Rev 2016;2016:CD009118.

6. Jaruvongvanich V, Patcharatrakul T, Gonlachanvit S. Prediction of delayed colonic transit using Bristol stool form and stool frequency in eastern constipated patients: A difference from the west. J Neurogastroenterol Motil 2017;23:561-8

7. MOVICOL. EA Pharma. Japan: User's Manual of MOVICOL; 2021. Available from: http://www.mochida.co.jp/dis/txt/pdf/mvc 5.pdf. [Last accessed on 2021 Jan 31]. 
8. Rajindrajith S, Devanarayana NM. Constipation in children: Novel insight into epidemiology, pathophysiology and management. J Neurogastroenterol Motil 2011;17:35-47.

9. Fujii Y, Morimoto T. Utility of mosapride citrate in pediatric functional constipation with low bowel frequency. Mathews J Pediatr 2019;4:20.

10. Fujii Y, Morimoto T. Utility of mosapride citrate combined with osmotic laxatives and probiotics in the initial treatment of pediatric functional constipation. Jpn J Gastroenterol Hepatol 2020;5:1-4.

11. Liu Z, Sakakibara R, Okada T, Uchiyama T, Uchiyama T, Yamamoto T, et al. Mosapride citrate, a novel 5-HT4 agonist and partial 5-HT3 antagonist, ameliorates constipation in Parkinsonian patients. Mov Disord 2005;20:680-6.

12. Komura M, Kanamori Y, Tanaka Y, Kodaka T, Sugiyama M, Terawaki K, et al. Mosapride for gastroesophageal reflex disease in neurologically impaired patients. Pediatr Int 2017;59:347-51.

13. Song BG, Lee YC, Min YW, Kim K, Lee H, Son HJ, et al. Risk of domperidone induced severe ventricular arrhythmia. Sci Rep 2020;10:12158.

14. Koppen IJ, Saps M, Lavigne JV, Nurko S, Taminiau JA, di Lorenzo C, et al. Recommendations for pharmacological clinical trials in children with functional constipation: The Rome foundation pediatric subcommittee on clinical trials. Neurogastroenterol Motil 2018;30:e13294.

15. van Summeren JJ, Holtman GA, Kollen BJ, Leeuwen YL, van UlsenRust AH, Tabbers MM, et al. Physiotherapy for children with functional constipation: A pragmatic randomized controlled trial in primary care. J Pediatr 2020;216:25-31.

16. Kim DH, Hyun SH, Shin SB, Kobayashi K. The role of intestinal bacteria in the transform of sodium picosulfate. Jpn J Pharmacol 1992;59:1-5.

17. Xu H, Xiong J, Xu J, Li S, Zhou Y, Chen D, et al. Mosapride stabilizes intestinal microbiota to reduce bacterial translocation and endotoxemia in $\mathrm{CCl}_{4}$-induced cirrhotic rats. Dig Dis Sci 2017;62:2801-11.

18. Takaki M, Goto K, Kawahara I, Nabekura J. Activation of 5-HT receptors facilitates neurogenesis of injured enteric neurons at an anastomosis in the lower gut. J Smooth Muscle Res 2015;51:82-94.

19. Kanazawa M, Watanabe S, Tana C, Komuro H, Aoki M, Fukudo S. Effect of $5-\mathrm{HT}_{4}$ receptor agonist mosapride citrate on rectosigmoid sensorimotor function in patients with irritable bowel syndrome. Neurogastroenterol Motil 2011;23:754-e332.

20. Gomes DO, de Morais MB. Gut microbiota and the use of probiotics in constipation in children and adolescents: Systematic review. Rev Paul Pediatr 2020;38:e2018123.

21. de Meij TG, de Grout EF, Eck A, Budding AE, Kneepkens CM, Benninga MA, et al. Characterization of microbiota in children with chronic functional constipation. PLoS One 2016;11:e0164731.

22. Míngues M, Hingueras AL, Júdez J. Use of polyethylene glycol in functional constipation and fecal impaction. Rev Esp Enferm Dig 2016;108:790-806.

23. Dziechciarz P, Wojtyniak K, Horvath A, Szajewska H. Enema versus polyethylene glycol for the management of rectal fecal impaction in children with constipation-a systematic review of randomized controlled trials. Prz Gastroenterol 2015;10:234-8.

24. Tajika M, Niwa Y, Bhatia V, Kawai H, Kondo S, Sawaki A, et al. Efficacy of mosapride citrate with polyethylene glycol solution for colonoscopy preparation. World J Gastroenterol 2012;18:2517-25.

Funding: None; Conflicts of Interest: None Stated.

How to cite this article: Fujii Y, Kouhata E, Kaneko K. Superiority of mosapride citrate to picosulfate sodium as a laxative for withdrawal from regular enemas in children with severe functional constipation. Indian J Child Health. 2021; 8(9):331-334. 